\section{Peroxidase Overproduction in Tomato: Wound-induced Polyphenol Deposition and Disease Resistance}

\author{
L. Mark Lagrimini', Jill Vaughn ${ }^{2}$, W. Alan Erb ${ }^{3}$, and Sally A. Miller ${ }^{4}$ \\ The Ohio State University, Columbus, OH 43210
}

\begin{abstract}
Additional index words. lignin, soluble phenols, Lycopersicon esculentum, Fusarium oxysporum f.sp. radicis-lycopersici, Fusarium oxysporum f.sp. lycopersici, Verticillium dahliae, tobacco mosaic virus, transgenic
\end{abstract}

Abstract. Lignin composition in leaf, fruit, and fruit outer epidermis of transgenic tomato (Lycopersicon esculentum Mill.) plants that overproduce the enzyme tobacco anionic peroxidase (TobAnPOD) was analyzed. This enzyme may catalyze the polymerization of cinnamyl alcohols into lignin in tobacco (Nicotiana tabacum L.); therefore, we predicted that its presence in the transformed tissue would increase lignin levels in healthy and wounded tissue. Lignin levels in healthy plants increased by $20 \%$ in leaf, $49 \%$ in fruit, and $106 \%$ in fruit outer epidermal tissue. Mature-green fruit were aseptically wounded and incubated in darkness for up to 7 days. Soluble phenols in wounded transgenic fruit increased by more than $300 \%$ hut changed little in control fruit. As with soluble phenols, lignin content in wounded transformed fruit increased by more than 20 -fold hut increased less than two-fold in control fruit. Transgenic seedlings overproducing TobAnPOD were screened for susceptibility to several pathogens, but resistance did not increase. Possible TobAnPOD roles in lignin biosynthesis, phenol metabolism, stress response, and disease resistance are discussed.

The plant cell wall is a primary defense against external threats, including pollutants, mechanical wounding, and intrusion by pathogenic microorganisms and insect pests. To defend the cell, the cell wall contains enzymes and substrates that can generate activated oxygen species and reactive phenolic radicals (Southerland, 1991) and erect barriers composed of cellulose, callose, lignin, and suberin (DeLeeuw, 1985). One cell wall enzyme that can catalyze many of these reactions is peroxidase. Peroxidases (EC 1.11.1.7, donor : hydrogen peroxide oxidoreductase) perform single electron oxidations on a wide variety of compounds in the presence of $\mathrm{H}_{2} \mathrm{O}_{2}$ or $\mathrm{O}_{2}$ (Gaspar et al., 1982). There are various peroxidase isoenzymes in plants derived from a large gene family. Recent reviews describe many biochemical and physiological functions of peroxidase (Everse and Grisham, 1991; Lobarzewski et al., 1991). Some of the proposed functions include cross-linking cell wall polysaccharides (Fry, 1986), lignification (Grisebach, 1981), wound healing (Espelie et

Received for publication 24 June 1992. Accepted for publication 12 Nov. 1992. Supported in part by a grant from the U.S. Dept. of Energy (DE-FG0289ER14004) to L.M.L. and by state and federal funds appropriated to the Ohio Agricultural Research and Development Center, The Ohio State Univ., Journal Article no. 182-92. The cost of publishing this paper was defrayed in part by the payment of page charges. Under postal regulations, this paper therefore must be hereby marked advertisement solely to indicate this fact.

Dept. of Horticulture; to whom reprint requests should be addressed.

${ }^{2}$ Dept. of Food Science and Technology.

${ }^{3}$ Dept. of Horticulture.

${ }^{4}$ Dept. of Plant Pathology. al., 1986), phenol oxidation (Uddin et al., 1888), and pathogen defense (Hammerschmidt et al., 1982). Reactions catalyzed by peroxidases, while indications of the plant's response to stress, complicate the understanding of peroxidase function in planta.

Evidence collected so far suggests that tobacco anionic peroxidase (TobAnPOD) is needed to form lignin. The purified enzyme has a preference for cinnamyl alcohols and readily will catalyze their polymerization into lignin in vitro (Mäder, 1980; Mäder et al., 1977). Also, histological and biochemical evidence shows that TobAnPOD is localized in the cell walls of lignifying tissue (Lagrimini, 1991b). However, the abundance of peroxidase isoenzymes makes it difficult to prove that TobAnPOD is the primary enzyme involved in lignin synthesis. To understand better the possible functions of this enzyme, transgenic tobacco plants that greatly overproduce this enzyme were engineered (Lagrimini et al., 1990). Resulting phenotypes included chronic wilting, wound-induced browning, and greatly enhanced lignin synthesis in response to wounding (Lagrimini, 1991a). These phenotypes suggest that this enzyme has significant physiological functions in addition to lignification. More recently, tomato plants have been transformed with the chimeric TobAnPOD gene to overproduce this enzyme in a heterologous system (Lagrimini et al., 1992). As in tobacco, these tomato plants were severely wilted, and, consequently, fruit size was greatly reduced. This gene was introduced into tomato because phenylpropanoid metabolism and lignin biosynthesis in response to wounding and infection are important factors determining the overall postharvest quality of processing and fresh-market tomatoes (Robinson,
1991). The phenylpropanoid pathway, which is induced by wounding, affects tomato color, flavor, and texture (Bell, 1981). Also, mechanical harvesting and handling frequently damage the fruit and trigger several woundspecific processes.

Plant materials and wounding. Unless otherwise stated, all plant transformations were performed with the early season processing tomato cultivar OH 7814 (Berry and Gould, 1983), which is susceptible to all of the tomato pathogens used in this study. The hybrid tomato 'OH 1498' was used as a control because it is resistant to all pathogens tested. Producing transgenic tomato plants that express TobAnPOD was described previously (Lagrimini et al., 1992). Briefly, 'OH 7814' stem segments were co-cultivated with Agrobacterium tumefaciens harboring either the plasmid pCib 10 (control), which confers kanamycin resistance, or pML 507 (POD overproducer), which is composed of a chimeric TobAnPOD gene transcribed from the cauliflower mosaic virus $35 \mathrm{~S}$ promoter inserted into pCib 10. Stem segments were placed on regeneration media containing kanamycin, shoots were rooted in potting soil, and plants homozygous for the foreign genes were selected through two generations of self-fertilizations. Tomato plants were propagated in the greenhouse with supplemental lighting (14-h photoperiod). One control plant (transformed with pCib 10) and two transgenic plants overproducing TobAnPOD (TobAnPOD 7-7 and TobAnPOD 7-B) were selected for further experiments.

Mature-green fruit were surface-sterilized briefly with $70 \%$ ethanol $(\mathrm{EtOH})$ followed by $10 \%$ commercial bleach for $10 \mathrm{~min}$, then wounded by aseptically cutting the fruit into two equal halves with a scalpel. The wounded sections were placed cut side up on moistened filter paper in petri dishes, sealed with parafilm, and incubated in darkness at $28 \mathrm{C}$. Tissues immediately frozen after excision were used as nonwounded controls.

Total soluble phenol and lignin determination. Total soluble phenol content was determined spectrophotometrically with the FolinDenis reagent on methanol $(\mathrm{MeOH})$ extracts of healthy and wounded tomato fruit (Swain and Hillis, 1959). A standard curve was generated with guaiacol. Lignin from leaf or fruit tissue was purified from an alcohol-insoluble cell wall fraction by preferentially solubilizing the lignin with thioglycolic acid using methods similar to those used by Bruce and West (1989) and Whitmore (1978). Tissue was homogenized (Polytron; Brinkman Industries, Westbury, N.Y.) in absolute $\mathrm{MeOH}$. Cell walls were pelleted by centrifugation, washed once in $\mathrm{MeOH}$, and pelleted again. The cell wall fraction was dried overnight at $60 \mathrm{C}$. Ten to $50 \mathrm{mg}$ of alcohol-insoluble residue was suspended in $5 \mathrm{ml}$ of $2 \mathrm{~N} \mathrm{HCl}$ and 0.5 $\mathrm{ml}$ of thioglycolic acid (Aldrich Chemical Co., Milwaukee) in tightly seated glass screwcap tubes. The tubes were placed in a 100C oil bath for $4 \mathrm{~h}$ and cooled to room temperature, and the lignin thioglycolate (LTGA) was pelleted by centrifugation at $30,000 \times \mathrm{g}$ for 10 
min at room temperature. The LTGA was washed once with $\mathrm{H}_{2} \mathrm{O}$ and solubilized in $5 \mathrm{ml}$ of $0.5 \mathrm{~N} \mathrm{NaOH}$ for $18 \mathrm{~h}$ at $25 \mathrm{C}$. The extract was cleared by centrifugation $(30,000 \times g, 10 \mathrm{~min})$, transferred to glass conical centrifuge tubes, and the supernatant acidified with $1 \mathrm{ml}$ of concentrated $\mathrm{HCl}$. The LTGA was precipitated at $4 \mathrm{C}$ for $4 \mathrm{~h}$ and the orange-brown precipitate pelleted by low-speed centrifugation. The LTGA was acid-base extracted once more to remove contaminants that absorb in the ultraviolet light spectrum. The final LTGA precipitate was dried and dissolved in $10 \mathrm{ml}$ of $0.5 \mathrm{~N} \mathrm{NaOH}$, and absorbance was measured at $280 \mathrm{~nm}$. A standard curve for lignin was generated with dehydroconiferyl alcohol polymerizate synthesized from coniferyl alcohol and horseradish peroxidase using the method of Kirk et al. (1975).

Infection of plants and quantification of disease resistance. Three Lycopersicon esculentum genotypes were assessed for their level of resistance to the pathogens Fusarium oxysporum f.sp. radicis-lycopersici (crown and root rot), $F$. oxysporum f.sp. lycopersici race 2 (wilt), Verticillium dahliae (wilt), and tobacco mosaic virus strain 4 (TMV) as described by Erb and Rowe (1992). The procedure differed in that seedlings were inoculated with one pathogen only, and inoculations with $V$. dahliae and TMV were done 2 weeks after seed was sown. The genotypes tested included ' $\mathrm{OH}$ 7814', 'OH 1498', and TobAnPOD 7-7, which overproduces TobAnPOD. Seeds were sown in a flat containing 10 to 20 seedlings per genotype. The data are represented as an average of three replications. Seedlings were evaluated for Fusarium crown and root rot 18 days after inoculation, Fusarium wilt 11 days after inoculation, and Verticillium wilt and TMV 4 weeks after inoculation. An equal number of mock-infected plants was used in parallel for all treatments. The criteria for rating disease susceptibility are provided in Fig. 1. TMV infection was assessed by enzyme-linked immunosorbant assay with a kit purchased from EIGHTY (Elkart, Ind.).

Lignin composition of transgenic tomato plants. TobAnPOD also is referred to as the lignin-forming peroxidase (Lagrimini et al., 1987). This activity was inferred from its spacial and temporal localization relative to lignified tissue in the tobacco plant (Lagrimini, 1991 b; Lagrimini and Rothstein, 1987; Mäder, 1980). This assumption leads us to predict that TobAnPOD expression in transgenic tomato plants may increase lignification, given that the enzyme is limiting in nonlignified tissues. This hypothesis was confirmed when the lignin composition was determined in leaf, fruit, and fruit outer epidermal tissues from tomato plants expressing TobAnPOD. Lignin was extracted with thioglycolic acid, which was preferable to other methods used on soft tissues with low lignin levels (Bruce and West, 1989). We were confident in analyzing lignin at concentrations $<1 \%$ of the total dry mass. The lignin content of leaf, fruit, and fruit outer epidermal tissues from peroxidase overproducer plants was higher than that in control plants (Table 1). This difference in lignifica- tion could arise from substrate availability or differential expression of the CaMV $35 \mathrm{~S}$ promoter. The observed increase in lignin in TobAnPOD-overproducing plants provides further evidence that the enzyme helps synthesize lignin.

Soluble phenol and lignin formation in wounded tomato fruit. Previous results with transgenic tobacco plants overproducing TobAnPOD indicated that the overproduction of this enzyme had a dramatic effect on woundinduced lignification and polyphenol metabolism (Lagrimini, 1991a). There were two reasons for examining the role of TobAnPOD in these secondary metabolic processes in tomato fruit: 1) fruit quality deteriorates from wounding, which can occur at several stages during harvest and postharvest handling, and 2) wounding leads to the production of many secondary metabolites that result in off-flavors, loss of firmness, and eventual decay (Haard,

A
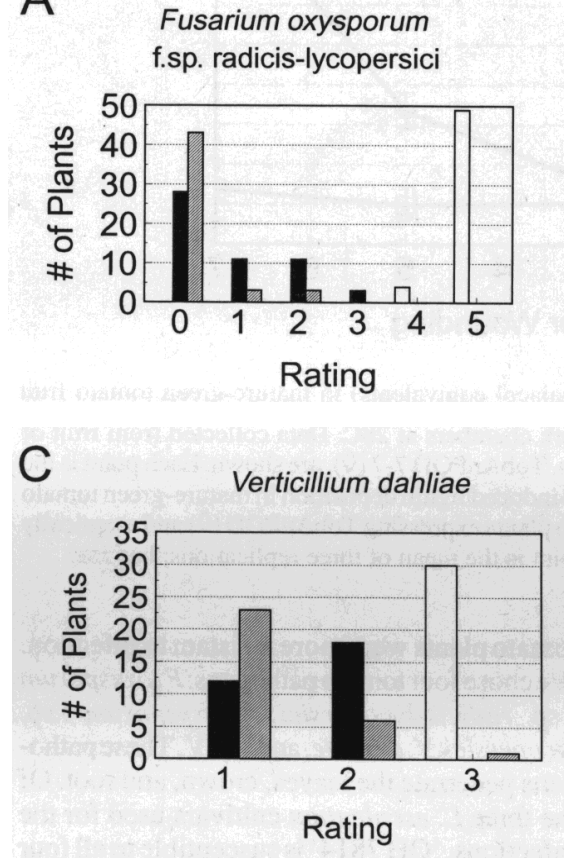

1977; Robinson, 1991). For these reasons, mature-green tomato fruit producing TobAnPOD were wounded, and total soluble phenols was quantified at $0,1,2,3,5$, and 7 days after wounding. Total soluble phenols in tomato fruit from control plants increased only slightly, even after 7 days (Fig. 2, top). However, soluble phenols rose rapidly-300\% increase in 7 days-in fruit producing TobAnPOD at high levels (>1600-fold). Consequentially, the high levels of TobAnPOD in the transformed tomato fruit significantly affected phenol metabolism during periods of stress, such as wounding. Just how an enzyme such as TobAnPOD affects soluble phenol concentration is unclear. Possibly, one or more substrates or products of a TobAnPOD-catalyzed reaction either directly or indirectly induces phenol synthesis in wounded tissue.

Wound-induced polymerization of phenol into lignin by TobAnPOD was also assessed.

\section{B Fussarium oxysporum f.sp. Iycopersici}

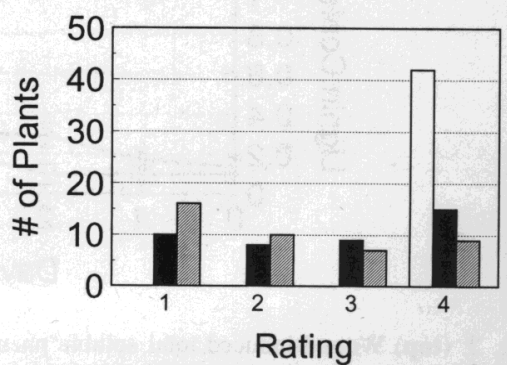

D

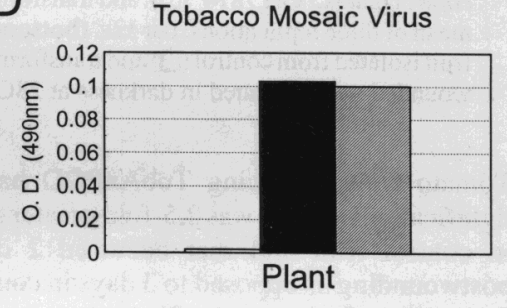

$\square \mathrm{OH} 1498 \square \mathrm{OH} 7814 \square$ TobAnPOD 7-7

Fig. 1. Disease susceptibility of transgenic tomato plants expressing TobAnPOD. Four tomato pathogens were used for quantifying disease resistance in three tomato cultivars: $\mathrm{OH} 1498$ (resistant), $\mathrm{OH} 7814$ (susceptible), and $\mathrm{OH}$ 7814TobAnPOD (producing tobacco anionic peroxidase). Three repetitions with 10 to 20 plants per repetition were used for each cultivar-pathogen pair. The rating system was defined as follows:

(A) Fusarium oxysporum f.sp. radicis-lycopersici: 0 = failed to germinate; $1=$ collapsed seedling; 2 = severe crown necrosis (shoot only slightly wilted or showing no symptoms); $3=$ moderate crown necrosis (shoot showing no symptoms): $4=$ slight crown necrosis (shoot showing no symptoms); and $5=$ healthy.

(B) Fusarium oxysporum f.sp. lycopersici: $1=$ severely stunted and wilted, $2=$ moderately stunted and wilted; 3 = slightly wilted and little or no stunting; and $4=$ healthy.

(C) Verticillium dahliae: 1 = severely stunted; 2 = moderate to slight stunting; and 3 = healthy.

(D) Tobacco mosaic virus strain 4 was quantified by ELISA, and data presented are the mean absorbances (three replications) at $490 \mathrm{~nm}$. The larger the number, the more virus in the tissue.

Table 1. Lignin composition in transgenic tomato plants producing tobacco anionic peroxidase. Percent change is with reference to the control plant ' $\mathrm{OH} 7814$ '. The mean $\pm \mathrm{EE}$ for three samples is expressed;

\begin{tabular}{|c|c|c|c|c|c|c|}
\hline \multirow[b]{2}{*}{ Plant } & \multicolumn{2}{|c|}{ Leaf } & \multicolumn{2}{|l|}{ Fruit } & \multicolumn{2}{|c|}{ Outer epidermis } \\
\hline & $\begin{array}{c}\text { Lignin } \\
(m e a n \pm \mathrm{SE})\end{array}$ & $\begin{array}{c}\text { Change } \\
(\%)\end{array}$ & $\begin{array}{c}\text { Lignin } \\
(m e a n \pm \mathrm{SE})\end{array}$ & $\begin{array}{c}\text { Change } \\
(\%)\end{array}$ & $\begin{array}{c}\text { Lignin } \\
(\text { mean } \pm \text { SE })\end{array}$ & $\begin{array}{c}\text { Change } \\
(\%)\end{array}$ \\
\hline$\overline{\text { Control }}$ & $0.393 \pm 0.040$ & 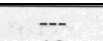 & $0.073 \pm 0.005$ & -- & $0.255 \pm 0.01$ & - \\
\hline TobAnPOD 7-7 & $0.467 \pm 0.032$ & 19 & $0.098 \pm 0.007$ & 34 & $0.407 \pm 0.02$ & 80 \\
\hline TobAnPOD 7-B & $0.474 \pm 0.049$ & 20 & $0.109 \pm 0.009$ & 49 & $0.525 \pm 0.02$ & 106 \\
\hline
\end{tabular}



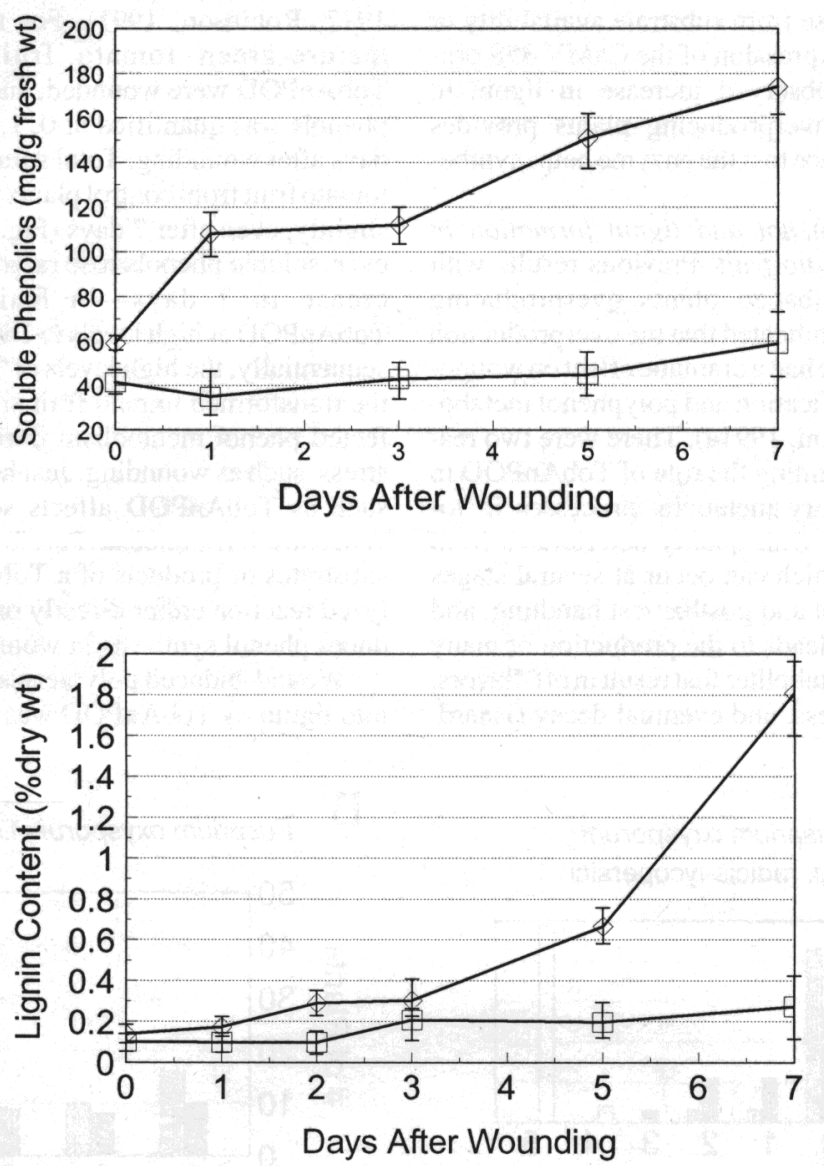

Fig. 2. (top) Wound-induced total soluble phenols (guaiacol equivalents) in mature-green tomato fruit wounded aseptically and then incubated in moist dark chambers at 28C. Data collected from fruit of control plants, 'OH 7814' ( $\square$ ), and transformed plants, TobAnPOD 7-7 $(\diamond)$ are shown. Each point is the mean of three replications: bar \pm SE. (bottom) Wound-induced lignin deposition in mature-green tomato fruit isolated from control $(\square)$ and transformed tomato plants expressing $\operatorname{TobAnPOD}(\nabla)$ and aseptically wounded and incubated in darkness at $28 \mathrm{C}$. Each point is the mean of three replications: bar \pm SE.

Tomato fruit producing TobAnPOD had a lignification rate that was 2.5 -fold greater than in control fruit and that occurred 2 days postwounding as opposed to 3 days in control fruit (Fig. 2, bottom). Plants producing TobAnPOD also showed lignification 1 18-fold higher than in control fruit at 7 days postwounding (data not shown). These results indicated that the low TobAnPOD activity in control fruit may restrict lignification rate and extent.

Peroxidase expression and disease resistance. A correlation between peroxidase expression, lignification, and disease resistance has been proposed for various crops (Dean and Kuc, 1987; Graham and Graham, 1991a; Southerton and Deverall, 1990; Ye at al., 1990a), including tomato (De Leeuw, 1985; Reuveni and Ferreira, 1985). This role may involve producing activated oxygen species or reactive phenol radicals (Southerland, 1991), or forming physical barriers constructed of lignin and suberin (DeLeeuw, 1985). However, the precise role remains to be determined. Transgenic tobacco and tomato plants overproducing TobAnPOD showed higher soluble phenol and lignin concentrations in healthy and wounded tissue. Based on this observation, we tried to determine if transgenic tomato plants were more resistant to infection. We chose four tomato pathogens: $F$. oxysporum f.sp. radicis-lycopersici, $F$. oxysporum f.sp. lycopersici, $V$. dahliae, and TMV. These pathogens penetrate the leaves, crown, and root. Of the three L. esculentum cultivars used for the infections, 'OH 7814' is susceptible to all four pathogens, TobAnPOD 7-7 (OH 7814) overproduces TobAnPOD, and OH 1498 is resistant to all four pathogens.

None of the plants producing TobAnPOD was more resistant to infection than the others. Thus, TobAnPOD expression in tomato plants failed to protect the young plants from infection by these pathogens (Fig. 1). There are several possible explanations for this result:

- This experiment was used on seedlings that were infected at a young age, and the amount of inoculum used was excessive. Mature field-grown tomato plants producing TobAnPOD may be field tolerant to the pathogens tested.

- Although the young seedlings overproduce TobAnPOD, there may not be the appropriate peroxidase substrates available in the infected tissues.

- Peroxidase-catalyzed reactions represent only one of several host responses to pathogenesis. Other responses include the pro- duction of chitinase, glucanase, phytoalexins, and hydroxyproline-rich glycoproteins (Dixon and Lamb, 1990).

- The primary mechanism for pathogen resistance used in this work involves processes other than peroxidase-mediated reactions. In several instances, plants overproducing peroxidase were more susceptible to infection. This result may be a consequence of the observed water stress (Lagrimini et al., 1992).

The results presented here demonstrate the dramatic effect on phenol metabolism in transgenic tomato plants producing TobAnPOD. Overproducing this one isoenzyme results in soluble phenol accumulation in healthy and wounded fruit and enhancement of wound-induced phenol metabolism. Lignin concentration was significantly higher in tomato fruit and fruit outer epidermis, and wound-induced lignin formation in genetically engineered tomato fruit was dramatically elevated compared to that of the control. However, under our conditions of infection, the overproduction of TobAnPOD did not make the plants resistant to any of the four pathogens tested.

\section{Literature Cited}

Bell, E.A. 1981. The physiological role of secondary (natural) products, p. 1-20. In: E.E. Conn (ed.). The biochemistry of plants. vol. 7. Academic, New York.

Berry, S.Z. and W.A. Gould. 1983. 'Ohio 7814' tomato. HortScience 18:494-496.

Bruce, R.J. and C.A. West. 1989. Elicitation of lignin biosynthesis and isoperoxidase activity by pectic fragments in suspension cultures of castor bean. Plant Physiol. 91:889-897.

DeLeeuw, G.T.N. 1985. Deposition of lignin, suberin and callose in relation to the restriction of infection by Botrytis cinerea in ghost spots of tomato fruits. Phytopathol. Z. 112:143-152.

Dean, R.A. and J. Kuc. 1987. Rapid lignification in response to wounding and infection as a mechanism for induced systemic protection in cucumber. Physiol. Mol. Plant Pathol. 31:69-81.

Dixon, R.A. and C.J. Lamb. 1990. Molecular communication in interactions between plants and microbial pathogens. Annu. Rev. Plant Physiol. Plant Mol. Biol. 41:339-367.

Erb, W.A. and R.C. Rowe. 1992. Screening tomato seedlings for multiple disease resistance. J. Amer. Soc. Hort. Sci. 117:622-627.

Espelie, K.E., V.R. Franceschi, and P.E. Kolattukudy. 1986. Immunocytochemical localization and time course of appearance of an anionic peroxidase associated with suberization in woundhealing potato tuber tissue. Plant Physiol. 81:487-492.

Everse, J. and M.B. Grishham. (eds.). 1991. Peroxidases in chemistry and biology. vol. II. CRC Press, Boca Raton, Fla.

Fry, S.C. 1986. Cross-linking of matrix polymers in the growing cell walls of angiosperms. Annu. Rev. Plant Physiol. 37:165-186.

Gaspar, T., C. Penel, T. Thorpe, and H. Greppin. 1982. Peroxidases: A survey of their biochemical and physiological roles in higher plants. Univ. of Geneva, Switzerland.

Graham, M.Y. and T.L. Graham. 1991a. Rapid accumulation of anionic peroxidases and phenolic polymers in soybean cotyledon tissues following treatment with Phytophthora 
megasperma f.sp. glycinea wall glucan. Plant Physiol. 97:1445-1455

Grisebach, H. 1981. Lignins, p. 457-478. In: E.E. Conn (ed.). The biochemistry of plants. vol. 7. Academic, New York.

Haard, N.F. 1977. Physiological roles of peroxidase in postharvest fruits and vegetables, p. 143-171. In: R.L. Ory and A.J. St. Angelo (eds.). Enzymes in food and beverage processing. Amer. Chem. Soc., Washington, D.C.

Hammerschmidt, R., E. Nuckles, and J. Kuc. 1982. Association of enhanced peroxidase activity with induced systemic resistance of cucumber to Colletotrichum lagenarium. Physiol. Plant Pathol. 20:73-82.

Kirk, T.K., W.J. Connors, R.D. Bleam, W.F. Hackett, and J.G. Zeikus. 1975. Preparation and microbial decomposition of synthetic $\left[{ }^{14} \mathrm{C}\right]$ lignins. Proc. Natl. Acad. Sci. USA 72:2515-2519.

Lagrimini, L.M. 1991a. Wound-induceddeposition of polyphenols in transgenic plants over-expressing peroxidase. Plant Physiol. 96:577-583.

Lagrimini, L.M. 1991b. Altered phenotypes in plants transformed with chimeric tobacco peroxidase genes, p. 59-67. In: J. Lobarzewski, H. Greppin, C. Penel, and T. Gaspar (eds.). Biochemical, molecular and physiological aspects of plant peroxidases. Univ. of Geneva, Switzerland.

Lagrimini, L.M., S. Bradford, and S. Rothstein.
1990. Peroxidase induced wilting in transgenic tobacco plants. Plant Cell 2:7-18.

Lagrimini, L.M. and S. Rothstein. 1987. Tissue specificity of tobacco peroxidase isoenzymes and their induction by wounding and tobacco mosaic virus infection. Plant Physiol. 84:438442.

Lagrimini, L.M., J. Vaughn, J. Finer, K. Klotz, and P. Rubaihayo. 1992. Expression of a chimeric tobacco peroxidase gene in transgenic tomato plants. J. Amer. Soc. Hort. Sci. 117:1012-1016.

Lobarzewski, J.,H. Greppin, C. Penel, and T. Gaspar (eds). 1991. Biochemical, molecular, and physiological aspects of plant peroxidases. Univ. of Geneva, Switzerland.

Mäder, M. 1980. Origin of the heterogeneity of peroxidase isoenzyme group Gl from Nicotiana tabacum. I. Conformation. Pflanzenphysiol. 96:283-296.

Mäder, M., N. Nessel, and M. Bopp. 1977. On the physiological significance of the isoenzyme groups of peroxidase from tobacco demonstrated by biochemical properties II. pH-optima, Michaelis-constants, maximal oxidation-rates. Z. Pflanzenphysiol. Bd. 82:247-260.

Reuveni, R. and J.F. Ferreira. 1985. Therelationship between peroxidase activity and the resistance of tomatoes (Lycopersicum esculentum) to Verticillium dahliae. Phytopathol. Z. 112: 193-197.
Robinson, D.S. 1991. Peroxidases and their significance in fruits and vegetables, p. 399-426. In: P.F. Fox (ed.). Food enzymology. Elsevier Applied Science, London.

Southerland, M.W. 1991. The generation of oxygen radicals during host plant responses to infection. Physiol. Mol. Plant Pathol. 39:79-93.

Southerton, S.G. and B.J. Deverall. 1990. Histochemical and chemical evidence for lignin accumulation during the expression of resistance to leaf rust fungi in wheat. Physiol. Mol. Plant Pathol. 36:483-494.

Swain, L. and W.E. Hillis. 1959. The phenolic constituents of Prunus domestica. I. The quantitative analysis of phenolic compounds. J. Food Agr. Sci. 10:63-68.

Uddin, R.M., S.Z. Berry, and A.D. Bisges. 1988. An improved shoot regeneration system for somaclone production in tomatoes. HortScience 23:1062-1064.

Whitmore, F.W. 1978. Lignin-carbohydrate complex formed in isolated cell walls of callus. Phytochemistry 17:421-425.

Ye, X.S., S.Q. Pan, and J. Kuc. 1990a. Activity, isozyme pattern, and cellular localization of peroxidase as related to systemic resistance of tobacco-to blue mold (Peronospora tabacina) and to tobacco mosaic virus. Phytopathology 80:1295-1298. 